\title{
Influence of inspiratory flow rate upon the effect of
} a Turbuhaler

\author{
S Pedersen, O R Hansen, G Fuglsang
}

\begin{abstract}
The effect of a new breath actuated dry powder inhaler, the Turbuhaler*, was found to be reduced at inhalations slower than 28 $1 /$ minute. This flow rate could be generated by virtually all children aged $\geqslant 6$ years, by 42 of 57 children $<6$ years $(74 \%)$, and by six of 15 preschool children with acute wheeze $(40 \%)$.
\end{abstract}

Many children with asthma cannot use a pressurised aerosol correctly and therefore gain little benefit from inhalation treatment with this device. In such cases dry powder inhalers may be a valuable treatment alternative. However, powder inhalers require a certain minimum inspiratory flow rate from the patient to work effectively. ${ }^{2}$ This limits the use of powder inhalers in children, whose inspiratory flow rate varies, both with age and expiratory pulmonary function.

Dry powder inhalers are designed in different ways and vary substantially in resistance to air flow. It is important, therefore, for physicians prescribing inhalation treatment for children to know in detail the peak inspiratory flow rate (PIFR) that various age groups can generate through an inhaler as well as the lowest inspiratory flow rate at which the inhaler will work effectively.

We conducted the present studies to answer these questions with regard to a new multidose powder inhaler, terbutaline Turbuhaler (Astra), which delivers pure freeze dried drug without any carrier substance or additives.

\section{Patients and methods}

\section{STUDY 1-MODES OF INHALATION}

Ten boys and four girls, aged 7 to 15 years (mean 10 years), participated in the study. All suffered from chronic or episodic wheeze associated with an increase in forced expiratory volume in one second $\left(\mathrm{FEV}_{1}\right)$ of at least $20 \%$ after one puff of terbutaline. All received regular inhaled treatment with $\beta_{2}$ stimulants, 12 received inhaled corticosteroids, and three slow release theophylline. The study was approved by the ethics committee of Northern Jutland, and informed consent was obtained from all children and their parents.

The design was that of a randomised, controlled double blind, double dummy crossover study. Each child participated on two separate occasions at the same time of the day. One day

Dr S Pedersen,

Department of Paediatrics, Kolding Hospital kk-6000 Kolding,

Denmark.

Accepted 20 September 1989
*The Turbuhaler is known as the Turbohaler in the United Kingdom. terbutaline was inhaled as fast as possible and another day at inspiratory flow rates around $22 \mathrm{l} /$ minute. When the results from these two days had been analysed the children participated for another two days, one at inspiratory flow rates around $30 \mathrm{l} / \mathrm{minute}$ and one at inspiratory flow rates around $10 \mathrm{l} /$ minute (randomised sequence). On each study day the children always inhaled from two different Turbuhalers, one containing terbutaline and one placebo. Different flow rates were used with the two inhalers to ensure the blinding of the study.

On all four days the children inhaled as deeply as possible from residual volume and the breath was held for 10 seconds after the inhalation.

To evaluate if maximum bronchodilation had been achieved by the inhaler treatment the children inhaled four puffs of terbutaline $(1 \mathrm{mg})$ from a pressurised aerosol with a Nebuhaler (Astra) at the end of each study day. Pulmonary functions were repeated 30 minutes after this treatment.

Before each visit, treatment with inhaled corticosteroids was stopped for 48 hours and treatment with $\beta_{2}$ agonists and theophylline for 12 hours

To be included in the study, pretreatment $\mathrm{FEV}_{1}$ had to be $\leqslant 70 \%$ of the predicted value or show a total increase $\geqslant 35 \%$ on each study day. Furthermore, a study on each child was only performed if the baseline $\mathrm{FEV}_{1}$ was within $15 \%$ of its value on the first study day, and if this was not the case the child was asked to make a further visit on another day.

The patients inhaled through a Turbuhaler in series with a pneumotachygraph. A total of 0.25 $\mathrm{mg}$ terbutaline was given on each study day and the children wore a nose clip during inhalation. Throughout the inhalation the children could see the variation with time of both inspiratory flow rate and inhaled volume on the screen of an oscilloscope. This was used as a teaching aid so that all children, after some practising in the morning, were able to make reproducible, standardised inhalations at a fixed inspiratory flow rate. Inspiratory flow rates and volume were recorded for analysis.

Pulmonary function was measured before, and at 30 minutes and at one, two, three, four, and five hours after each inhaler treatment. The measurements were performed on a Vitalograph with a pulmonary function analyser and the bronchodilator response was assessed by measuring changes in $\mathrm{FEV}_{1}$, forced vital capacity (FVC), forced midexpiratory flow rate (FMEF), and peak expiratory flow rate (PEFR). Both absolute values and percentage 
change were evaluated. The best of three measurements was studied.

STUDY 2-PIFR IN NORMAL CHILDREN

To evaluate the maximum inspiratory flow rates that various age groups of children can generate through the Turbuhaler, 265 children aged between 3.5 and 15 years were taught to inhale as quickly and deeply as possible through the inhaler in series with the pneumotachygraph. The flow and volume time curves were recorded and the best of three measurements was analysed. In addition, PEFR was measured on a Mini Wright peak flow meter, and $\mathrm{FEV}_{1}$ and FVC on a Vitalograph (best out of three). These measurements were done in all children in a kindergarten and a small state school who were able to cooperate.

\section{STUDY 3-ACUTE ASTHMA}

Thirty four asthmatic children aged between 4 and 13 years (mean $7 \cdot 4$ years) were studied as described in study 2 during an episode of acute wheeze at the outpatient clinic.

\section{STATISTICS}

Friedman's test was used to evaluate any overall difference between treatments. Both absolute values, percentage change, and area under the time/pulmonary function curves $\left(\mathrm{AUC}_{0-300}\right)$ were evaluated. If significant effects for treatment or time were found the results were analysed by Wilcoxon's rank sum test. A $p$ value of $<0.05$ was considered significant.

\section{Results}

MODES OF INHALATION

All 14 children completed the study. No period or carry over effects were found and no side effects observed.

Mean PIFR was $60 \mathrm{l}$ /minute (range 47-72) during fast inhalations and 31 (range 28-33), 22 (range 20-24), and 13 (range 12-15) 1/minute during the three other treatments. The corres-

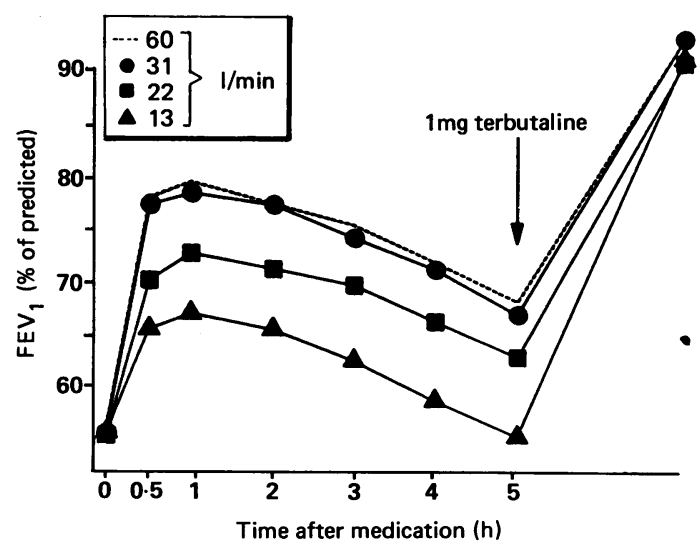

Figure 1 Mean $F E V$, as a percentage of the predicted value after inhalation of $0.25 \mathrm{mg}$ terbutaline from $a$ Turbuhaler at four different flow rates. At five hours $1 \mathrm{mg}$ terbutaline was inhaled from a Nebuhaler. ponding mean inhaled volumes were $1 \cdot 9,1 \cdot 8$, 1.4 , and 1.51 , respectively; 1.41 being significantly lower than 1.8 and $1.91(\mathrm{p}<0.05)$

The $\mathrm{FEV}_{1}$ as a percentage of the predicted value before and after the four Turbuhaler treatments is shown in fig 1 . There was no significant difference between the initial $\mathrm{FEV}_{1}$ on the four days of treatment. The $\mathrm{FEV}_{1}$ before treatment varied from $40 \%$ to $82 \%$ (mean $58 \%$ ) of the predicted value.

All inhalations resulted in a significant increase in $\mathrm{FEV}_{1}$, which lasted throughout the study period for inhalations at 60 and 31 $1 /$ minute and for four and three hours for inhalations at 22 and $13 \mathrm{l} /$ minute, respectively. There was no difference between the response after inhalation at $60 \mathrm{l} /$ minute and inhalations at 31 $1 /$ minute. The improvement after both these treatments was significantly greater than that after inhalations at $22 \mathrm{l} /$ minute $(\mathrm{p}<0.01)$. Furthermore, reducing the inspiratory flow rate to $13 \mathrm{l} /$ minute diminished bronchodilation even further $(p<0.01$ compared with inhalations at $22 \mathrm{l} /$ minute), so that $\mathrm{AUC}_{0-300}$ was only $33 \%$ of the $A U_{0-300}$ after flow rates around 60 $1 /$ minute.

After all four modes of inhalation the Nebuhaler treatments given at the end of the day resulted in additional increases in $\mathrm{FEV}_{1}$ as compared with maximum FEV 1 after Turbuhaler treatment $(p<0.01)$, indicating that maximum bronchodilation had not been achieved by any of the Turbuhaler treatments.

The results were similar for FMEF, PEFR, and FVC except that the change in FMEF after inhalations at $31 \mathrm{l} /$ minute was significantly lower than the change in FMEF after inhalations at $60 \mathrm{l} /$ minute. Furthermore, the increase in FVC after inhalations at $221 /$ minute was similar to that measured after inhalations at 60 and $31 \mathrm{l} /$ minute.

PIFR OF NORMAL CHILDREN

PIFR varied significantly with age $(r=0.83$; $\mathrm{p}<0.01$ ) (fig 2) and with PEFR ( $r=0.90$; $\mathrm{p}<0.01$ ). In addition, inhaled volume was found to correlate significantly with FVC $(\mathrm{r}=0.79 ; \mathrm{p}<0.01)$. Fifteen out of 57 children $<6$ years of age were unable to generate an inspiratory flow rate of $28 \mathrm{l} /$ minute. Apart from

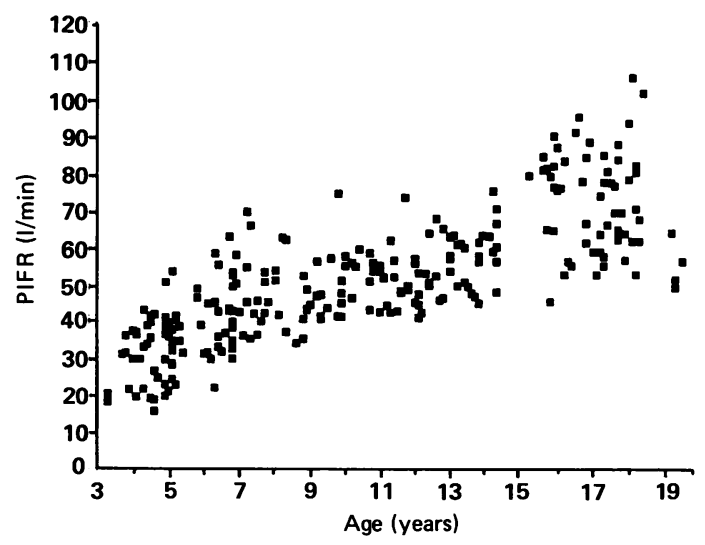

Figure 2 PIFR through a Turbuhaler in various age groups of 265 normal children. 
one 6 year old child, who generated an inspiratory flow rate of $22 \mathrm{l} /$ minute, the inspiratory flow rates of the remaining 208 children $\geqslant 6$ years were higher than $31 \mathrm{l} /$ minute.

\section{ACUTE ASTHMA}

Mean PIFR measured during the acute attacks of bronchoconstriction in 15 children aged 4 and 5 years (mean PEFR $=87 \mathrm{l} /$ minute) was 24 $1 /$ minute (range $14-36 \mathrm{l} /$ minute). Nine of these children could not generate an inspiratory flow rate of $28 \mathrm{1} / \mathrm{minute}$. This was also the case for two of 19 wheezing children $\geqslant 6$ years. The remaining 17 children in this age group all generated inspiratory flow rates between 30 and $54 \mathrm{l} /$ minute (mean $=39 \mathrm{l} /$ minute). Mean PEFR in the older children was $135 \mathrm{l} /$ minute (range= 80-180 1/minute).

\section{Discussion}

When the influence of inspiratory flow rate was studied we used half the normal terbutaline dose in the Turbuhaler. On no occasion did this dose result in maximum bronchodilation. Therefore, the comparison between the four treatments took place on the steep part of the dose-response curve where differences are detected more easily than if maximum bronchodilation had been achieved by the Turbuhaler treatment. Under these conditions it was found that the effect of the Turbuhaler was retained down to inspiratory flow rates around $30 \mathrm{l} / \mathrm{min}$ ute whereas inspiratory flow rates from 30 $1 /$ minute and downwards were associated with a decreasing response. This is in good accordance with the results of various in vitro studies showing that although the dose delivered from the Turbuhaler does not vary with flow rate, the amount of respirable drug particles $(<5 \mu)$ decreases with decreasing flow rate so that the amount of particles $<5 \mu$ is about $50 \%$ lower at flow rates around $221 /$ minute as compared with flow rates around $60 \mathrm{l} /$ minute (Astra, personal communication). Therefore, the reduced effect at low inspiratory flow rates seems to be due to insufficient breaking up of the large drug particles in the mouthpiece insert due to insufficient energy supply from the inspiration. We do not know exactly at which flow rate the Turbuhaler will stop working but it still retained about $33 \%$ of its effect at flow rates around $13 \mathrm{l} /$ minute, which is well beyond the lowest flow rate measured in any of the 265 normal children and most of the 34 asthmatic children with acute wheeze. For comparison the Rotahaler (Allen and Hanburys) has earlier been found to retain only about $10 \%$ of its maximum effect at inspiratory flow rates around $40 \mathrm{l} / \mathrm{minute}-\mathrm{a}$ flow rate that about a quarter of children younger than 6 years could not generate. ${ }^{1}$

Our findings showed that children should be taught to inhale as fast as possible when using the Turbuhaler. Such advice is simple and, due to the rather high resistance of the inhaler, will not result in unacceptably rapid inspiratory flow rate, which would increase the likelihood of a more central deposition of drug in the bronchial tree. ${ }^{34}$

Virtually all children $\geqslant 6$ years were able to generate an inspiratory flow rate of $30 \mathrm{l} /$ minute, indicating that they would all be able to benefit optimally from Turbuhaler treatment. About a quarter of children aged 3-5 years, however, could not generate this inspiratory flow rate under basic conditions. Further, this number was even higher during attacks of acute bronchoconstriction or in periods of poor control of symptoms. Therefore it will be necessary to increase the inhaled dose or to use other inhalation devices in such situations in the younger age groups. This is in accordance with the recommendations with other powder inhalers, ${ }^{12}$ though there seem to be differences between the various inhalers in their susceptibility to a reduced inspiratory flow rate and critical flow rate beyond which the inhaler will not work at all. ${ }^{5}$

A reduction in inhaled volume of 0.51 has earlier been found not to affect the response from Turbuhaler treatment. ${ }^{6}$ Therefore, it is most unlikely that the small difference in inhaled volume between treatments at inspiratory flow rates around $22 \mathrm{l} /$ minute and treatments at higher flow rates influenced the results in the present study.

We conclude that asthmatic children using a Turbuhaler should be taught to inhale as quickly as possible. Young children may gain less benefit from the treatment because they cannot generate sufficiently high inspiratory flow rates through this inhaler, especially during episodes of acute bronchoconstriction. This may also be the case for a few older children during episodes of severe wheeze.

1 Pedersen S. How to use a Rotahaler. Arch Dis Child 1986;61:11-4.

2 Pedersen S, Steffensen G. Fenoterol powder inhalation technique in children: influence of inspiratory flow rate and breath-holding. Eur $\mathcal{F}$ Respir Dis 1986;68:207-14.

3 Dolovich M, Ruffin RE, Roberts R, Newhouse MT. Optimal delivery of aerosols from metered dose inhalers. Chest 1981;80:911-5.

4 Newman SP, Pavia D, Clarke SW. Effects of various inhalation modes on the deposition of radioactive pressurized aerosols. Eur 7 Respir Dis 1982;63(suppl 119):57-65.

5 Pedersen S. Inhaler use in children with asthma. Dan Med Bull 1987;34:234 49 .

6 Ramsgaard Hansen O, Pedersen S. Optimal inhalation technique with terbutaline Turbuhaler. Eur $\mathcal{F}$ Respir Dis 1989 ; 2:637-9. 